\title{
BMJ Open Safety and efficacy of larval therapy on treating leg ulcers: a protocol for systematic review and meta-analysis
}

\author{
Weijing Fan, ${ }^{1,2}$ Baozhong Yang, ${ }^{3}$ Xiaoming Hu, ${ }^{1}$ Xiao Yang, ${ }^{1}$ Chenyan Shi, ${ }^{1}$ \\ Guobin Liu (i) ${ }^{1}$
}

To cite: Fan W, Yang B, Hu X, et al. Safety and efficacy of larval therapy on treating leg ulcers: a protocol for systematic review and meta-analysis. BMJ Open 2020;10:e039898. doi:10.1136/ bmjopen-2020-039898

- Prepublication history for this paper is available online. To view these files, please visit the journal online (http://dx.doi. org/10.1136/bmjopen-2020039898).

Received 29 April 2020 Revised 04 July 2020 Accepted 10 September 2020

Check for updates

(c) Author(s) (or their employer(s)) 2020. Re-use permitted under CC BY-NC. No commercial re-use. See rights and permissions. Published by BMJ.

${ }^{1}$ Peripheral vascular disease department, Shuguang Hospital Affiliated to Shanghai University of Traditional Chinese Medicine, Shanghai, China

${ }^{2}$ Shanghai University of Traditional Chinese Medicine, Shanghai, China

${ }^{3}$ Peripheral vascular disease department, Dongfang Hospital Affiliated to Beijing University of Chinese Medicine, Beijing, China

Correspondence to

Dr Guobin Liu; 18811023202@126.com and Dr Baozhong Yang; 18601026336@163.com

\section{ABSTRACT}

Introduction Leg ulcers (LUs) not only seriously affect life and work of patients, but also bring huge economic burden to the society. As a potential underused biological debridement, larval therapy provides help for the treatment of LUs. The purpose of our research is to assess whether patients with LUs can benefit from larval therapy. Methods and analysis The following electronic databases will be searched: PubMed, EMBASE, Web of Science, the Cochrane Library, China National Knowledge Infrastructure Database, Wanfang Database and Chinese Biological Medicine. Randomised controlled trials are eligible for inclusion. There will be no restrictions with respect to language and search date is up to June 2020. Primary outcomes investigated are complete healing rate after treatment, time to ulcer healing, reduction of wound surface area and adverse events. Risk ratios will be used for categorical data; weighted mean difference will be used for measurement data. Subgroup analysis and sensitivity analysis will be considered if heterogeneity exists. The results of data synthesis will be performed by narrative summary and quantitative analysis.

Ethics and dissemination This systematic review does not require the approval of the ethics committee because individual data on patients are not collected. The results of the study will be disseminated in peer-reviewed journals. PROSPERO registration number CRD42020176953.

\section{INTRODUCTION}

Leg ulcers (LUs) are defined as hard-to-heal wounds that develop below the knee on the leg or foot. ${ }^{1}$ The main causes of ulceration are varied and complicated, the primary reasons include chronic venous insufficiency of lower extremities, diabetes and peripheral arterial disease. ${ }^{2}$ These ulcers have become a serious public health problem all over the world. It is estimated that between $10 \%$ and $25 \%$ of the population with diabetes have diabetic foot ulcers (DFUs). ${ }^{3}$ More than 50 million people will have DFUs by $2030 .^{4-7}$ According to epidemiological studies, in the United Kingdom of Great Britain and Northern Ireland (UK), $0.1 \%-0.3 \%$ individuals have Venous leg ulcers (VLUs) at any time. $^{8}$ The overall costs of treating venous

\section{Strengths and limitations of this study}

This study will be the first systematic review and meta-analysis analysing larval therapy in the treatment of patients with leg ulcers (LUs).

- This systematic review and meta-analysis will follow the Preferred Reporting Items for Systematic Reviews and Meta-Analyses guidelines.

- Different types of LUs may cause considerable heterogeneity in this review.

- Because there is no unified practice for larval therapy at present, different methods of operation in application may lead to differences in debridement effect.

LUs is estimated to be $£ 300-600$ million in the UK and $\$ 1$ billion in the USA per year. ${ }^{910}$ LUs greatly affect the sleep and interpersonal relationship of patients, reduce the quality of life and then cause huge economic losses for patients, resulting in a considerable cost to the healthcare system.

It is generally accepted by healthcare providers that the presence of necrotic tissue and slough will delay the healing of wounds and debridement (removing dead or dying tissue from the surface of a wound) can shorten the time of wound healing. ${ }^{11-14}$ There are various ways of debridement, such as mechanical debridement, enzymatic debridement and biosurgical debridement. Larvae (sterile maggots) as a debriding agent is the most commonly used method of biosurgical debridement. Mouth hooks and rough bodies of the maggots can play the role of mechanical debridement during the movement of maggots, while the mixture of proteolytic they secrete may transform nonviable tissue into substances that are easier to digest for the maggots. ${ }^{15-18}$ It has been considered that larval therapy debrides wounds more effectively and safely than standard treatments. ${ }^{19-21}$ In addition, studies have shown that use of larval therapy can reduce the bacterial load 
on the wound.$^{22-24}$ Larval therapy is a promising tool for health professionals dealing with difficult LUs.

The specific question addressed by the review is: Is the use of larval therapy effective and safe in the treatment of LUs in patients?

\section{METHODS}

\section{Criteria for included studies}

Types of studies

All randomized controlled trials (RCTs) comparing larval therapy with no larvae or usual care in adults with LUs. Full-text reports in any language will be included.

\section{Types of patients}

Adult patients (aged 18 years or older) diagnosed with LUs (including DFUs, arterial LUs, venous LUs or mixed LUs) will be included in this study.

\section{Types of interventions}

The intervention will include any type of larval therapy compared with no larvae or usual care in people with LUs.

Types of outcome measures

Primary outcomes:

- Complete healing rate after treatment.

- Time to ulcer healing.

- Reduction of wound surface area.

- Adverse events, including amputations, infection and pain.

Secondary outcomes:

- Health-related quality of life.

- Cost.

- Ulcer recurrence.

\section{Search methods for the identification of studies}

Electronics searches

We will systematically search following databases from inception to June 2020: PubMed, Web of Science, EMBASE, Cochrane Library, Wanfang Database, China National Knowledge Infrastructure Database and Chinese Biological Medicine. There are no language restrictions.

The following search terms will include: "larva", "maggot", "biosurgery", "bio-surgery", "larval therapy", "leg ulcers", "leg ulcer", "chronic leg ulcers", "diabetic foot ulcers", "diabetic ulcers", "venous leg ulcers", "venous leg ulcer", "venous ulcer", "varicose ulcer", "gravitational ulcers", "venous hypertension ulcer", "venous stasis ulcer", "randomised controlled trial", "clinical trial", "trial". Search strategies have been created and adjusted to the different databases. The search strategy for PubMed is shown in table 1.

\section{Searching other resources}

We will examine the references of the included studies so that we can find any research that has not been found. At the same time, we will use International Clinical Trials Registry Platform of WHO to search ongoing trials or unpublished trials.
Table 1 Search strategy used in PubMed database

\begin{tabular}{|c|c|}
\hline \multicolumn{2}{|c|}{ Search strategy (PubMed database) } \\
\hline NO & Search terms \\
\hline \#1 & leg ulcers (MeSH, Medical Subject Headings) \\
\hline \#2 & leg ulcer \\
\hline \#3 & Ulcer, Leg \\
\hline \#4 & Ulcers, Leg \\
\hline \#5 & venous ulcer \\
\hline \#6 & Varicose Ulcer \\
\hline$\# 7$ & Foot Ulcer \\
\hline \#8 & Diabetic Ulcer \\
\hline \#9 & arterial ulcer \\
\hline \#10 & chronic leg ulcers \\
\hline \#11 & diabetic foot ulcers \\
\hline \#12 & venous leg ulcers \\
\hline \#13 & Venous Hypertension Ulcer \\
\hline \#14 & Venous Stasis Ulcer \\
\hline \#15 & gravitational ulcers \\
\hline \#16 & $\begin{array}{l}\# 2 \text { OR \#3 OR \#4 OR \#5 OR \#6 OR \#7 OR \#8 OR } \\
\# 9 \text { OR \#10 OR \#11 OR \#12 OR \#13 OR \#14 \#15 }\end{array}$ \\
\hline \#17 & larval therapy (MeSH) \\
\hline \#18 & larval therapy \\
\hline \#19 & Larvae \\
\hline \#20 & Maggots \\
\hline \#21 & Maggot \\
\hline \#22 & biosurgery \\
\hline \#23 & bio-surgery \\
\hline \#24 & \#18 OR \#19 OR \#20 OR \#21 OR \#22 \#23 \\
\hline \#25 & Randomized controlled trial (MeSH) \\
\hline \#26 & Randomized controlled trial \\
\hline \#27 & Controlled clinical trial \\
\hline \#28 & Clinical trial \\
\hline \#29 & trial \\
\hline \#30 & \#26 OR \#27 OR \#28 OR \#29 \\
\hline \#31 & \#16 AND \#24 AND \#30 \\
\hline
\end{tabular}

Selection of studies

Two reviewers ( $\mathrm{WF}$ and $\mathrm{XY}$ ) will independently screen the research according to the criteria. The titles and abstracts are the main contents of the review, and the full text of the relevant research will be reviewed if necessary. Any disagreements will be arbitrated by a third reviewer (BY). The reasons for all excluded studies will be recorded. We will include a study flow diagram as recommended by the Preferred Reporting Items for Systematic Reviews and Meta-Analyses statement, as shown in figure 1.

\section{Data extraction and management}

The following information will be extracted by two independent reviewers (XH and $\mathrm{XY}$ ): reference ID, 


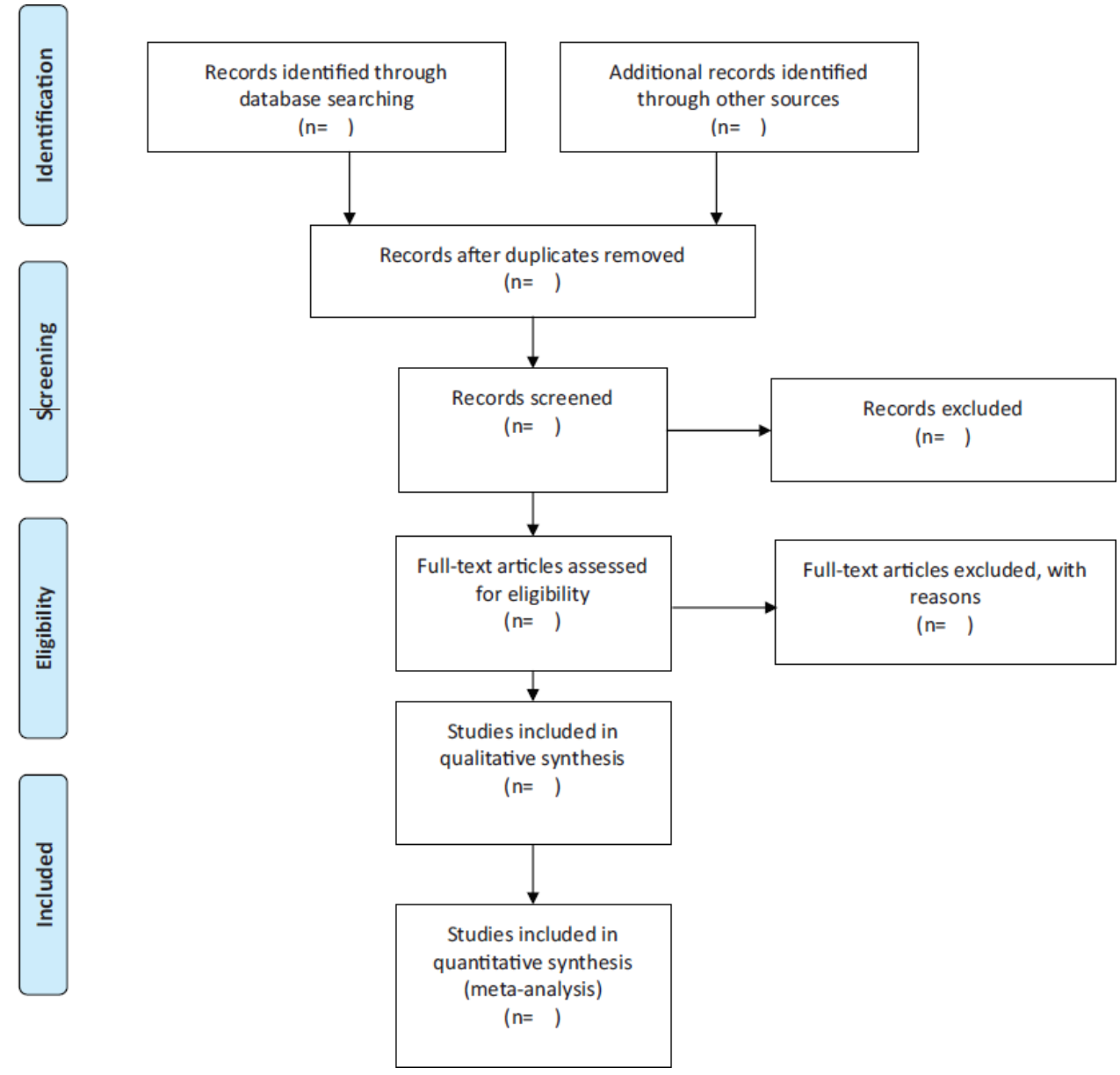

Figure 1 The Preferred Reporting Items for Systematic Reviews and Meta-Analyses flow chart.

publication date, author names, baseline characteristics of participants per treatment arm, study samples, number of participants randomised to each treatment arm, study design, country of origin, larval therapy intervention, control intervention, duration of treatment, outcomes at all reported time points, adverse effects, follow-up, source of trial funding and so on. Information not recorded in the research report will be obtained by contacting the corresponding author. Any disagreements will be arbitrated by a third reviewer (GL). All data will be entered into the RevMan software (V.5.3) after double cross-checking.

\section{Assessment of risk of bias in included studies}

The assessment of risk of bias will be conducted in accordance with the Cochrane Handbook standards and will include the following seven aspects: selection bias (random sequence generation); selection bias (allocation concealment); implementation bias (blinding of researchers and implementers); measurement bias (results of the blind evaluation); follow-up bias (completeness of outcome data); reporting bias (results of selective reporting) and other sources of bias. ${ }^{25}$ Each item will be divided into three levels : low risk, high risk and unclear. The evaluation will be conducted independently by two reviewers (WF and CS), and any disagreements will be arbitrated by consulting a third-party expert (GL).

\section{Measures of treatment effect}

We plan to perform data analysis using RevMan V.5.3 provided by the Cochrane Collaboration. We plan to present the dichotomous outcomes with risk ratios and 95\% CIs. We will report estimates for continuous data as weighted mean difference and 95\% CIs. Standardised mean difference will be used if different measurement tools were used in different trials.

\section{Dealing with missing data}

Reviewers (WF and XY) will attempt to contact the corresponding author to obtain the missing data. A sensitivity analysis will be conducted to address the potential impact of lost data If necessary.

\section{Assessment of heterogeneity}

$\chi^{2}$ test ( $p$ value $<0.10$ ) will be used for investigating statistical heterogeneity. We will use $\mathrm{I}^{2}$ statistic to measure heterogeneity among the trials in each analysis. If the heterogeneity test shows little heterogeneity in these trials $\left(\mathrm{I}^{2}<50 \%\right)$, a fixed effect model will be used to combine statistical effects. The random-effect model will be used for moderate heterogeneous data $\left(50 \%<\mathrm{I}^{2}<75 \%\right)$. If there is considerable heterogeneity ( $\left.\mathrm{I}^{2}>75 \%\right)$, meta-analysis will not be conducted. 


\section{Assessment of reporting bias}

Reporting bias will be assessed using funnel plot analysis if a minimum of 10 studies were available for the metaanalysis of primary outcomes.

\section{Subgroup analysis}

We plan to carry out the following subgroup analyses if data are available:

Type of LUs (venous LUs, arterial LUs, mixed LUs, etc).

The duration of treatment.

We will use the formal test for subgroup interactions in Review Manager. ${ }^{26}$

\section{Sensitivity analysis}

A sensitivity analysis will be conducted to determine whether our results are robust. We will exclude the studies with high risk for bias from the summary analysis and analyse them again to assess the impact of these studies on the results.

\section{Grading the quality of evidence}

The Grading of Recommendations Assessment, Development, and Evaluation (GRADE) guidelines will be used to assess overall quality of the evidence. The GRADE system is a subjective evaluation of the quality of the evidence as very low, low, moderate or high based on the existence or degree of five factors: limitation of study design, imprecision, inconsistency, indirectness and bias of publication. ${ }^{27}$

\section{Ethics and dissemination}

This systematic review does not require the approval of the ethics committee because individual data on patients are not collected. The results of the study will be disseminated in peer-reviewed journals.

\section{Patient and public involvement}

Patients and or public were not involved.

\section{DISCUSSION}

As a potentially underused method of biological debridement, larval therapy can not only play the role of mechanical debridement, but also play the role of enzymatic debridement, which provides the possibility to speed up the healing of LUs. ${ }^{28} 29$

This meta-analysis will provide a relatively convincing conclusion as to whether patients with LUs can benefit from larval therapy.

\section{Amendments}

This is an original research protocol, any changes will be stated in the final review manuscript and updated via PROSPERO.

Contributors WF and GL designed the systematic review. WF and BY drafted the manuscript. WF and XY will search the research. WF, XH, XY and CS will extract and analyse the data. All the authors have read the protocol and approved its publication.

Funding This work was supported by the National Natural Science Foundation of China (No. 81774310; №. 81804095).
Competing interests None declared.

Patient and public involvement Patients and/or the public were not involved in the design, or conduct, or reporting, or dissemination plans of this research.

Patient consent for publication Not required.

Provenance and peer review Not commissioned; externally peer reviewed.

Open access This is an open access article distributed in accordance with the Creative Commons Attribution Non Commercial (CC BY-NC 4.0) license, which permits others to distribute, remix, adapt, build upon this work non-commercially, and license their derivative works on different terms, provided the original work is properly cited, appropriate credit is given, any changes made indicated, and the use is non-commercial. See: http://creativecommons.org/licenses/by-nc/4.0/.

ORCID iD

Guobin Liu http://orcid.org/0000-0002-6598-8545

\section{REFERENCES}

1 Scottish Intercollegiate Guidelines Network (SIGN). Management of chronic venous leg ulcers: a national clinical guideline, 2010. Available: https://www.wwic.wales/uploads/files/documents/ Professionals/Venous\%20Leg\%20Ulcer/sign120.pdf [Accessed 20 May 2016].

2 Mekkes JR, Loots MAM, Van Der Wal AC, et al. Causes, investigation and treatment of leg ulceration. Br J Dermatol 2003;148:388-401.

3 Armstrong DG, Hanft JR, Driver VR, et al. Effect of oral nutritional supplementation on wound healing in diabetic foot ulcers: a prospective randomized controlled trial. Diabetic Medicine 2014;31:1069-77.

4 Alavi A, Sibbald RG, Mayer D, et al. Diabetic foot ulcers: part II management. J Am Acad Dermatol 2014;70:21.e1-124.

5 Leone S, Pascale R, Vitale M, et al. Epidemiology of diabetic foot. Infez Med 2012;20:8-13.

6 Nather A, Bee CS, Huak CY, et al. Epidemiology of diabetic foot problems and predictive factors for limb loss. J Diabetes Complications 2008;22:77-82.

7 Bakri FG, Allan AH, Khader YS, et al. Prevalence of diabetic foot ulcer and its associated risk factors among diabetic patients in Jordan. J Med J 2012;46:118-25.

8 NICE, National Institute for Health and Care Excellence. Clinical knowledge summaries: leg ulcer - venous, 2015. Available: https://cks.nice.org.uk/leg-ulcervenous_escaped_fragment_= topicsummary\#!to picsummary

9 Margolis D, Bilker W, Knauss J. The incidence and prevalence of pressure ulcers among elderly patients in general medical practice. Ann Epidemiol 2002;12:321-5.

10 Department of Health. Prescription Cost Analysis - England, 2006, 2007. Available: https://digital.nhs.uk/data-and-information/ publications/statistical/prescription-cost-analysis/prescription-costanalysis-2006

11 Ayello E, Baranoski S, Kerstein M, et al. Wound debridement. In: Baranoski S, Ayello E, eds. Wound care essentials practice principles. Philadelphia: Lippincott Williams and Wilkins, 2004: 117-25.

12 Gupta A. A review of the use of Maggots in wound therapy. Ann Plast Surg 2008;60:224-7.

13 NICE, National Institute of clinical excellence. Guidance on the use of debriding agents and specialist wound care clinics for difficult to heal surgical wounds, 2008. Available: http://www.nice.org.uk/ nicemedia/ $\mathrm{pdf} / \mathrm{CG} 74$.

14 Steed DL, Donohoe D, Webster MW, et al. Effect of extensive debridement and treatment on the healing of diabetic foot ulcers. Diabetic ulcer study group. J Am Coll Surg 1996;183:61-4.

15 Blake FAS, Abromeit N, Bubenheim M, et al. The biosurgical wound debridement: experimental investigation of efficiency and practicability. Wound Repair and Regeneration 2007;15:756-61.

16 Gottrup F, Jorgensen B. Maggot debridement: an alternative method for debridement. Eplasty 2012;11:e33.

17 Brown A, Horobin A, Blount DG, et al. Blow fly Lucilia sericata nuclease digests DNA associated with wound slough/eschar and with Pseudomonas aeruginosa biofilm. Med Vet Entomol 2012;26:432-9.

18 Jarczyk G, Jackowski M, Szpila K, et al. Use of Lucilia sericata blowfly maggots in the treatment of diabetic feet threatened with amputation. Acta Angiologica 2008;14:42-55.

19 Dumville JC, Worthy G, Bland JM, et al. Larval therapy for leg ulcers (Venus II): randomised controlled trial. BMJ 2009;338:b773.

20 Malekian A, Esmaeeli Djavid G, Akbarzadeh K, et al. Efficacy of maggot therapy on Staphylococcus aureus and Pseudomonas 
aeruginosa in diabetic foot ulcers: a randomized controlled trial. $J$ Wound Ostomy Continence Nurs 2019;46:25-9.

21 Mudge E, Price P, Walkley N, Neal W, et al. A randomized controlled trial of larval therapy for the debridement of leg ulcers: results of a multicenter, randomized, controlled, open, observer blind, parallel group study. Wound Repair Regen 2014;22:43-51.

22 Blake FAS, Abromeit N, Bubenheim M, et al. The biosurgical wound debridement: experimental investigation of efficiency and practicability. Wound Repair Regen 2007;15:756-61.

23 Arora S, Baptista C, Lim CS. Maggot metabolites and their combinatory effects with antibiotic on Staphylococcus aureus. Ann Clin Microbiol Antimicrob 2011;10:6.

24 Jaklič D, Lapanje A, Zupančič K, et al. Selective antimicrobial activity of maggots against pathogenic bacteria. J Med Microbiol 2008;57:617-25
25 Green S, Higgins JP. Cochrane Handbook for systematic reviewsof interventions version 5.1.0 (updated March 2011). The Cochrane collaboration, 2011. handbook.cochrane.org

26 Nordic Cochrane Centre, The Cochrane Collaboration. Review manager 5 (RevMan 5). version 5.3. Copenhagen: Nordic Cochrane Centre, The Cochrane Collaboration, 2014.

27 Guyatt GH, Oxman AD, Vist GE, et al. Grade: an emerging consensus on rating quality of evidence and strength of recommendations. $B M J$ 2008;336:924-6.

28 Wilasrusmee C, Marjareonrungrung M, Eamkong S, et al. Maggot therapy for chronic ulcer: a retrospective cohort and a meta-analysis. Asian J Surg 2013.

29 Wayman J, Nirojogi V, Walker A, et al. The cost effectiveness of larval therapy in venous ulcers. J Tissue Viability 2000;10:91-4. 